from the body altogether; a portion of the vagus, sufficiently long to permit of its easy irritation, should be left. When the heart is excised, the sinus can be irritated more FIG. 52.

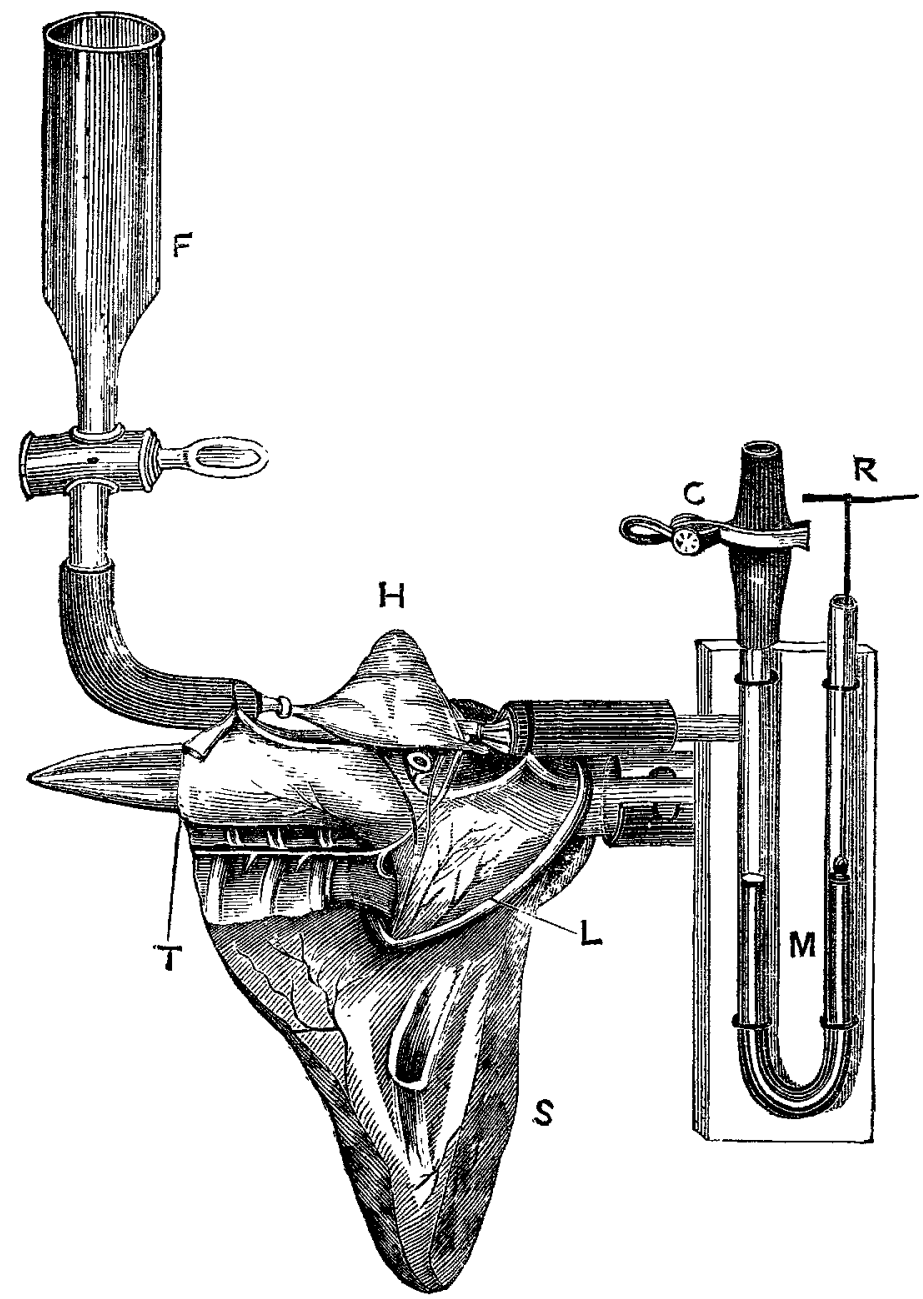

Apparatus for studying the influence of the vagus or the influence of poisons upou the frog's heart.-M, Mercurial manometer connected with aorta. R, A pin for seratching a trace upon a blackened cylinder. $\quad c$, Clip upon a piece of caontchouc tubing. H, Heart. L, Lower jaw. s, Skin. T, A glass tube thrust through the esophagus. F, Funnel with stopcock. This is flled with serum from rabbits' blood, and being connected with nozzle in the inferior vena cava, serum can be introduced into the heart when required. The sympathetic nerve is seen lying alongside the vertebræ. The vagus is seen extending between the heart and the angle of the jaw. (Slightly altered from Coats : Ludwig's Arbeiten, 1871.)

readily when required. When the influence of a poison is to be observed, it is added to the serum of rabbits' blood. After tracings such as that represented in Fig. 53 have

FIG. 53.

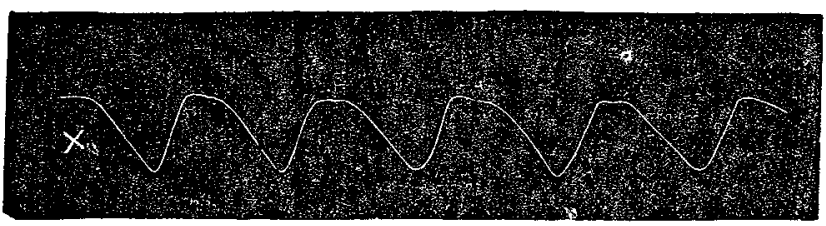

Tracing taken from a manometer in connexion with the ventricle of a frog's heart (Fig. 52). This tracing is taken from an unpoisoned heart.

been obtained from the heart supplied with normal serum, poisoned serum is placed in the funnel, and is permitted to low through the heart. For example, suppose we feed the neart with serum containing nicotine. We should find that while irritation of the trunk of the vagus fails to retard ihe heart's action, the retardation takes place on irritating she sinus of the heart. This results from the terminal portion of the inhibitory part of the nerve mechanism $n$ the heart having escaped the paralysing influence of ;he poison. If atropine be given instead of the nicotine, rritation of the vagus trunk is as powerless to affect the 1eart as in the case of nicotia palsy; but in the case of itropia, irritation of the sinus does not inhibit the heart, secause the peripheral terminations of the inhibitory apsaratus are palsied by atropia.
ON A

\section{CASE OF DEFECT OF SPEECH FOLLOWING} A RIGHT-SIDED CONVULSION.

BY J. HUGHLINGS JACKSON, M.D., F.R.C.P., PHYSICIAN TO THE LONDON HOSPITAL, AND TO THE HOSPITAI FOR THE BPILEPTIC AND PARALYSED.

IN the "Mirror" of The LANCET, March 18th, 1871, is a brief note of remarks I made on cases of temporary loss and defect of speech with certain epileptiform seizures (epileptic aphasia). The following case, there referred to, was reported by Mr. Stephen Mackenzie. It is not often that one has the chance of observing a patient who talks badly soon after an epileptiform seizure, and therefore this case has great value. In most cases the defect after the fit, so far as one can learn from the patient's friends, is slight, or the accounts we receive are very vague. The great merit of Mr. Mackenzie's report is that it is a faithful record of what actually took place, and possesses infinitely more value than if he had contented himself with mere statements as to the nature of the defect. I have, however, one critical remark to make on it. The patient was not asked to write during the continuance of the defect of speech ; but notwithstanding this omission, the report is the most valuable one I possess of the manner of talking after a one-sided convulsion. Hence it may seem most ungracious of me to draw attention to the omission; but I need not hesitate, for the reporter, knowing thoroughly well the importance of investigating the writing powers of patients who have defect of speech, would himself, were he publishing the case, be certain to draw attention to his omission. As mentioned in the "Mirror," those fits in which speech is much affected usually start in the right cheek, but it must be admitted that occasionally there is temporary defect of speech when the fit begins in the hand. In the following case it was only ascertainable that the fit affected the right side.

Martha Faughty, aged seventeen. Her name is given because it is possible that the frequent use of the word "forty" may, so to speak, have been determined by the fact that the similarly sounding word, Faughty, would be one of the most automatic in her vocabulary. Mr. Mackenzie begins his report by alluding to trouble she had had from a wrongful accusation. The patient was a healthy-looking woman, and, as will be seen later in the report, no evidence of organic disease was discovered in the heart or kidneys. The rest of the report is in Mr. Stephen Mackenzie's words.

"Nov. 13th, 1870.-Her uncle says that the patient visited him to-day. During or after tea she had what he calls a fainting fit-that is to say, she turned very pale, and seemed to lose, at least partially, her consciousness, not answering when spoken to, and being unable to swallow water. She was laid down, and when a little recovered her uncle proposed to her to go out, thinking the open air would revive her. He got her into the street by supporting her, and whilst walking along she had a fit. $\mathrm{He}$ says that the head was drawn down to the right shoulder, the mouth was drawn to the right, and that her right arm was drawn up towards her head and stiffened. He spoke to her, but she could not answer him. He got her into a cab and brought her to the hospital. On her way there she vomited. The nurse in the receiving-room noticed that 'her mouth was drawn,' and that she kept her right arm semi-flexed. When I saw her she was able to walk into the women's dressing-room. She kept her right arm bent so that the hand came to about the waist, whilst the left arm she carried naturally. Her face was very pale, but there was no difference between its two sides. Eyes natural ; pupils large, probably not abnormal. I asked her to put out her tongue. She did so readily. It was clean, and not bitten. I then asked her if she was in pain. She said, 'Yes, sir.' When I asked her where, she again said, 'Yes, sir.' When asked what was her name, she said 'No.' When desired to place either of her hands in mine, she did so with each equally well. I then asked, 'Where do you live?' She replied, 'Quite Chris.' I said, interrogatively, 'Quite Chris?' and she replied, 'Twenty Chris.' I then again asked her her name. She replied, 'Thank you, sir.' 'How old are you ?' 'Thank you, sir.' 'Are you cold ?' 'Yes, sir.' 'Have you had your dinner ?' 
'Yes, sir.' 'Have you been sick?' 'Yes, sir, having tea-c.' 'Have you any brothers or sisters?' ' $\mathrm{N}-\mathrm{e}-\mathrm{c}-\mathrm{k}$ ' (spelled rapidly). 'What is to-day?' 'N-e-c.k.' 'Is it Sunday?' 'N-e-c-k.' 'What was yesterday?' 'C-k.' 'What did you have for dinner?' 'Oh, n-e-c-k.' 'How did you get to your uncle's to-day??' 'Oh, any length.' 'When did you leave your situation?' ' Oh, when you like' -(correcting herself) ' $\mathrm{Oh}$, when you will.' 'What is your mistress's name?' 'Oh-n-c.' 'Has she any children?' ' No-c.' ' What is your master's employment?' 'Oh-n-c.' 'Have you been to church to-day?' 'Oh-n-c.' 'What church?' 'That's all.' 'How long have you left it?' ' Oh, altogether yet.'

"Her articulation was clear. She did not seem annoyed at being asked questions, nor at her own replies; and, with very few exceptions, she did not attempt to correct herself. She laid herself down on the couch at full length. She was sent up to bed.

"When visited about half an hour after in the ward, I said, 'What is your name?' She replied 'Martha Faughty. 'How long have you been in service?' 'Forty years.' "Where does your master live?" '40, Clerkenwell-green." 'Where does your father live?' '40, Clerkenwell-green.' 4 40, Clerken well-green?' ‘ 41 , Clerkenwell-green.' 'What had you for dinner?' 'Forty.' She then answered 'Yes' to several consecutive questions, and then 'No.' 'What are your wages?' 'Forty pounds.' 'How much is that a month?' 'Four pounds.' 'Count twelve.' She did so readily without mistake. 'What is twice twelve?' 'Twenty-four.' 'What is twice forty?' 'Twenty-two.' 'How many pennies are there in a shilling?' "Twenty.' 'How many threepenny-pieces in a shilling?' 'Sixpence.'

"Her upper extremities were very cold, but the trunk was warm, and the skin dry. She had perfect sensibility and power in both legs, and knew right from left when touched. Feet warm. Perfect sensibility of upper extremities, and conld place either hand in mine when asked to do so. Tongue clean, and protruded in middle line. Left pupil slightly larger than right. The difference was extremely slight. Pulse 104, excessively small and feeble, so much so that it was with difficulty found. Respiration 18 , almost entirely abdominal, but not at all laboured. Temperature : right axilla, $97 \cdot 8^{\circ} \mathrm{F}$; left, $97 \cdot 8^{\circ}$. Heart and lung sounds normal.

"Louis Mackenzie held up his fingers, and asked how many there were. Sometimes she answered correctly, and sometimes incorrectly. She did not seem able to calculate, for when he held up seven fingers she said 'eight'; and when he asked her how she made that out, she said, 'five before, and two, that's eight.' Though generally right as to the number, she made mistakes as to the addition, as 'five and one is nine.'

"Nov. 14th.-(The following notes are by Mr. Louis Mackenzie).-She recognises me on coming to her bedside, and laughs on my asking her several questions. She answers with perfect ease and accuracy. She says that she woke up this morning about 4 o'clock, and wondered where she was. She states that she went to her uncle's yesterday about 4.30 P.M., having dined at 3 . She had a cup of tea at her uncle's, and a small slice of bread and butter. She had swallowed three or four damson stones at her dinner with her pie. She was sick soon after tea, and they took her into the wash-house. Soon afterwards she felt sleepy, and then she remembers nothing more, except that her uncle put his hat on the table. She remembers that we asked her many questions last night, but she does not remember answering at all. She 'remembers listening to all we had to say,' but she said very little herself. She remembers my saying, "You see she does not know when I hold up my fingers.' Pulse 96 ; respiration 18 ; temperature, right axilla $99^{\circ} \mathrm{F}$, left $98 \cdot 8^{\circ}$. Has no pains in the head. No abnormal sounds to be heard at the heart. Urine : specific gravity 1030, acid; no albumen, no sugar. Erening: Got up for a short time this afternoon, but had to lie down again.

"15th. - Slept well. Tongue clean; appetite good; bowels freely open after an aperient. When she got up to-day she felt giddy, and had a shivering, although she was warm. No nausea nor vomiting. Has no pain in the head, but has pain in her back of an aching character. This is probably connected with menstruation, as she has 'seen nothing' the last five or six weeks. There is a crop of herpes labialis. She cannot see distinctly, as atropiue has been put into her eyes. This will perhaps account for her giddiness when up. There are no abnormal ophthalmoscopical appearances. Pulse 92. Respiration 28 . Temperature : right axilla, $98 \cdot 6^{\circ}$; left axilla, $99 \cdot 4^{\circ}$.-Evening : She states that about midday she gradually became very hot, and then broke out into a sweat. There had been slight shivering in the morning; but no distinct rigor nor cardiac murmur. Pulse 96, small but regular. Respiration 18; vesicular murmur is heard all over the chest. Temperature: right axilla, $97^{\circ} 4^{\circ}$; left axilla, $980^{\circ}$. Nothing wrong can be felt in the rectum, uterus, or vagina.

"16th.-Says she has an 'awful pain' in the back. Has been perspiring very freely through the night. Pulse 96. Respiration 22. Temperature: left axilla, $98.8^{\circ}$; right axilla, 98.4.-Evening: She states that she is very hot, and perspires more than ever. Pain in her back worse than ever. Some vesicular spots about the left nostril, which are painful. No sickness. Feels thirsty; tongue clean and moist. Pulse 92. Respiration 20. Temperature in left axilla, $97 \cdot 2^{\circ}$.

"17th.-Evening: Pulse 104. Respiration 20. Temperature: right axilla, $99^{\circ}$; left axilla, $988^{\circ}$. In less pain, and feels stronger.

"18th.-Says she feels much better. Began to menstruate this morning, when the pain left her back. When she gets out of bed she feels cold, and has "pins and needles' in both legs. Pulse 84. Respiration 20. Temperature: left axilla, $982^{\circ}$; right axilla, $97 \cdot 6^{\circ}$.-Evening : Pulse 84. Respiration 20. Temperature: left axilla, $982^{\prime}$; right axilla, $97 \cdot 2^{\circ}$.

"19th. - 'Pins and needles' gone. Extremities cold Pulse 100. Respiration 18. Temperature: right axilla, $99 \cdot 6^{\circ}$; left axilla, $99 \cdot 9^{\circ}$

"21st.-Menstruation ceasing. Went out."

In March, 1871, she was again seen by Mr. Stephen Mac. kenzie; she had remained well.

What the illness she had on recovery from the nervous seizure was $I$ do not know. It is possible that the case may be considered by some as hysterical or emotional, especially as the poor woman had very good reason to be depressed ir spirits from the unjust treatment she had received; but the convulsive seizure, so far as the description enabled me t judge, is not such as occurs in hysterical women, and is like those which occur from disease of the brain. A convulsior which affects one side of the body must, I presume, depenc on local changes of some kind; and I infer that the locatior is the region of the corpus striatum. What those change are there is no evidence to show. Granting the reality 0 the seizure, it is obvious that there was a sudden discharg of nerve-tissue; but we cannot say by what pathologica process the local change permitting that discharge wa brought about. It may be supposed to depend on embolisn or thrombosis; but there is no evidence to support this con clusion. In most cases of convulsion beginning unilaterall there is no evidence to show the nature of the pathologica process from which the " discharging lesion" results.

Manchester-square, Dec. 1871.

\section{TREATMENT OF CONICAL CORNEA BT} REMOVAT $_{i}$ OF THE TOP OF THE CONE.

\section{Br C. B A D E R}

OPHTHALMIC ASGISTANT-SURGEON, GUY'S HOSPITAL.

The favourable results obtained by the operation of re moving the top of the cone in conical cornea must justif the publication of the following cases in extenso. The firs case was operated on in 1863.* Since then, up to Augus 1871, nine cases have been treated in the same manner: $i$ seven cases the left eye, in one the right, and in one bot eyes were operated on.

\section{The Operation.}

1. Place the patient on a bed as for extraction of catarac and bring him thoroughly under chloroform.

2. Keep the eyelids open with a stop-speculum, so as $t$ * See page 192 of my book on the Natural and Morbid Changes of $t$ Human Eye. 